\title{
The Anodic Surface Film and Hydrogen Evolution on $\mathrm{Mg}$
}

\author{
Guang-Ling Song*, Kinga A. Unocic \\ Oak Ridge National Laboratory, Oak Ridge, Tennessee 37831, USA \\ *guangling.song@hotmail.com; Songg@ornl.gov; +1 865-574-4451
}

\section{Abstract}

This study clarifies that the inner and outer layers of the anodic film consist of a nano/micro-porous $\mathrm{MgO}+\mathrm{Mg}(\mathrm{OH})_{2}$ mixture. The film becomes thicker and more porous with increasing potential. It can rupture when potential is too positive in a non-corrosive $\mathrm{Mg}(\mathrm{OH})_{2}$ solution. Hydrogen evolution becomes more intensive as polarization potential increases, particularly when the potential at the film-covered Mg surface is close to or more positive than the hydrogen equilibrium potential, suggesting that an "anodic hydrogen evolution" (AHE) reaction occurs on the substrate Mg in film pores, and the significantly intensified AHE causes film rupture at high potential.

Keywords: A. Mg; B. EIS; B. TEM; B. SEM; C. anodic dissolution; C. negative difference effect. 


\section{Introduction}

Mg is one of the lightest engineering and biocompatible metals. However, its poor corrosion resistance limits its industrial applications [1,2]. To address the corrosion issue, its anodic dissolution behavior must be comprehensively understood.

Mg has a negative standard equilibrium potential, around -2.4V/SHE (SHE=Standard Hydrogen Electrode) $[3,4]$, and open-circuit potentials ( -1.5V/SHE) in corrosive solutions [5]. Its highly active surface is covered under an oxide/hydroxide film [6, 7]. The influence of surface film on corrosion of $\mathrm{Mg}$ and its alloys has been widely studied [8-26]. However, most of the investigations were mainly focused on the films formed at Open-Circuit Potentials (OCPs). There are very few publications showing the film composition and microstructure on $\mathrm{Mg}$ at anodic potentials [17]. How the film evolves with increasing anodic potential has not yet been systematically studied.

In fact, the formation and dissolution of a surface film is primarily determined by potential. Anodic polarization can alter the integrity and stability of a film, making Mg more active or passive [27-32]. It has been reported that the film continuity/integrity can determine the Negative Difference Effect (NDE) or "Anodic Hydrogen Evolution" (AHE) behavior of anodically polarized Mg [33], although the detailed NDE mechanism is still a focus of controversy [34-36]. In case that Mg 
alloys are in contact with other engineering metals, they are always anodically polarized by the coupling metals [37], and their galvanic corrosion performance can be influenced substantially by their anodic films [38]. Even on a naturally exposed Mg alloy, its surface film can actually evolve with varying OCP. Therefore, illustration of the film composition and microstructure at different potentials will be a prerequisite to solving the corrosion or biodegradation problem of Mg alloys.

\section{Experimental}

To eliminate the influence of alloying elements and intermetallic phases on film composition and microstructure, pure $\mathrm{Mg}$ (Al:0.009wt.\%, Zn:0.003wt.\%, Cu<wt.0.01\%, Fe:0.008wt.\%, Mn:0.011wt.\%, Ni<0.001wt.\%) was used [22]. Electrodes made of the Mg ingot with $1 \mathrm{~cm}^{2}$ exposed working area were abraded with SiC paper up to P\#1200.

Saturated $\mathrm{Mg}(\mathrm{OH})_{2}$ (pH10.5) was used as testing solution to simplify the film composition on the Mg. The testing solution can also ensure a constant solution $\mathrm{pH}$ value for better experimental reproducibility [39]. The solution resistivity was measured to be $883 \Omega \cdot \mathrm{cm}$ using a conductivity meter.

Polarization curve and AC electrochemical impedance spectroscopy (EIS) measurements were conducted using a potentiostat (Parstat 4000, Princeton Applied Research) in a three-electrode electrolyte cell containing $450 \mathrm{~mL}$ testing 
solution with a Saturated Calomel Electrode (SCE, which has an equilibrium potential $0.241 \mathrm{~V}$ more positive than a SHE) as reference and a $1 \mathrm{x} 1$ inch platinum foil as auxiliary electrode. The SCE was inserted into a Luggin capillary and the capillary tip was placed in front of the Mg electrode surface. To avoid hydrogen bubbles evolved from the Mg surface being trapped by the capillary tip and blocking the reference electrode, the distance of the capillary tip to the Mg surface was carefully controlled around 6 7 mm. The Mg electrode was held at a starting potential (e.g., $1.7 \mathrm{~V} / \mathrm{SCE}$ ) in the solution for 0.5 hour to record its potentiostatic polarization current density, then EIS was measured at this potential using a $10 \mathrm{mV}$ RMS ACpotential signal in a frequency range from $10 \mathrm{kHz}$ to $5 \mathrm{mHz}$. After that, the potentiostatic polarization potential was increased to a higher potential and held at this new potential for 0.5 hour to record a new potentiostatic current density. EIS measurement was also repeated at this new potential after current density recording. In this manner, as the potentiaostatic potential became higher and higher step by step, a series of potentiostatic polarization current densities and EISs at different potentials were obtained. The potentiostatic polarization curve of $\mathrm{Mg}$ is a plot of potentiostatic polarization current densities versus their corresponding potentiostatic potentials.

Hydrogen was collected in a burette through a funnel mounted over the $\mathrm{Mg}$ electrode at different potentials using the same counter and reference electrodes in a beaker containing $1 \mathrm{~L}$ testing solution [40]. 
The Mg electrodes after 24 hour polarization at different potentials were examined with 3D Digital Optical Microscopy (OM, VHX-1000, Keyence), Scanning Electron Microscopy (SEM, Hitachi model S3400 and S4800) and Scanning Transmission Electron Microscopy (STEM/TEM, Philips model CM200). TEM specimens were prepared by focus-ion-beam in-situ lift-out technique (Hitachi NB5000 FIB-SEM).

\section{Results and discussion}

\subsection{Anodic polarization and hydrogen evolution}

The measured anodic potentiostatic polarization curve (Figure 1(a)) shows a gradually increasing anodic current density with increasing potential, which cannot be distinctly divided into two regions. However, after IR-correction is performed according to equation $\mathrm{V}_{\text {True }}=\mathrm{V}-\mathrm{I} \mathrm{R}_{\mathrm{s}}$ (where I is measured potentiostatic current density, $\mathrm{R}_{\mathrm{s}}$ is solution resistance obtained from EIS, which is the real part of the impedance at frequency $10 \mathrm{k} \mathrm{Hz}$ in this study, $\mathrm{V}$ is experimentally applied potentiostatic potential, and $V_{\text {True }}$ is the IR-corrected potential), the anodic current density curve bends up evidently when $V_{\text {True }}$ is higher than a transition potential $E_{\text {Ip }}$ $\left(\mathrm{E}_{\mathrm{Ip}} \approx-1.03 \mathrm{~V}_{\text {True }} / \mathrm{SCE}\right.$ on the IR-corrected curve, corresponding to $\sim-0.85 \mathrm{~V} / \mathrm{SCE}$ on the experimental curve). In this study, $\mathrm{E}_{\mathrm{Ip}}$ is not only a potential denoting the change in anodic current density increasing trend, but also signifies a change in $\mathrm{Mg}$ surface film microstructure, which will be further illustrated later. 
The hydrogen evolution rate from $\mathrm{Mg}$ surface (which is a film-covered surface) increases with increasing potential (Figure 1(b)). It accelerates with time at potentials above $-0.8 \mathrm{~V} / \mathrm{SCE}$ (Figure $1(\mathrm{c}$ )). Particularly at $0 \mathrm{~V} / \mathrm{SCE}$ and $2 \mathrm{~V} / \mathrm{SCE}$, the hydrogen evolution dramatically accelerates. These two potentials correspond to $0.84 \mathrm{~V}_{\text {True }} / \mathrm{SCE}$ (i.e., $-0.60 \mathrm{~V}_{\text {true }} / \mathrm{SHE}$ ) and $-0.80 \mathrm{~V}_{\text {True }} / \mathrm{SCE}$ (i.e., $-0.56 \mathrm{~V}_{\text {true }} / \mathrm{SHE}$ ), respectively, very close to and higher than the hydrogen equilibrium potential ($0.60 \mathrm{~V}_{\text {true }} / \mathrm{SHE}$ ) in the saturated $\mathrm{Mg}(\mathrm{OH})_{2}$ solution (pH10.5) [4]. If the hydrogen evolution was a cathodic reaction, it should have ceased or stopped at a potential more positive than positive $-0.84 \mathrm{~V}_{\text {true }} / \mathrm{SCE}$. The experimental observation (Figure 1) suggests that the hydrogen evolution is unlikely to be a simple proton reduction reaction on a film-covered Mg surface.

\subsection{Electrochemical parameters of anodically polarized $\mathrm{Mg}$ surface}

Mg in the testing solution has two capacitive loops in EIS. The validity of these loops has been conformed by K-K transformation in the study. The inductance features in the low frequency range $(<0.1 \mathrm{~Hz})$ are not very clear because of the scattered data points. These capacitive and inductive characteristics are shown in Figure 2(a), which presents three typical EISs measured at different potentials.

An equivalent circuit (Figure 2(b)) is proposed to curve-fit the measured EISs. The components/parameters of the circuit have the following meanings: 
$R_{s}$ : the solution resistance between reference electrode and the surface of the film-covered Mg electrode,

$\mathrm{R}_{\mathrm{f}}$ : the surface film resistance, which is mainly determined by the film porosity and the solution conductivity in the film pores,

$R_{a}$ : the pseudo resistance for electrochemical reactions at film/Mg interface, which is dependent on the reactivity of the substrate $\mathrm{Mg}$ with the solution in film pores,

$\mathrm{R}_{\mathrm{L}}$ : the inductive resistance for electrochemical reactions at film/Mg interface.

$C_{f}$ : the surface film capacitance, whose value is proportional to film porosity and reciprocal to film thickness,

$\mathrm{C}_{\mathrm{a}}$ : the pseudo capacitance for electrochemical reactions at film/Mg interface, and

$\mathrm{L}$ : the inductance for electrochemical reactions at film/Mg interface.

There is always a non-Faradaic process during EIS measurement, which can be simulated by a capacitance in the equivalent circuit. On a film-covered electrode, the non-Faradaic process is mainly determined by the film capacitance $\mathrm{C}_{\mathrm{f}}$ in parallel with Faradaic reactions. The Faradaic process of a film-covered Mg electrode should consist of reactions in the film and at the film/Mg interface. The resistance through the film is denoted as $R_{f}$, which is in series with the reactions at the film/Mg interface. The complicated electrochemical reactions at the film/Mg interface can be equivalent to a pseudo capacitance $C_{a}$ in parallel with a pseudo capacitive resistance $R_{a}$ and a pseudo inductance $L$ in series with a pseudo inductive resistance $\mathrm{R}_{\mathrm{L}}$.

The data points at low frequencies $(<0.1 \mathrm{~Hz})$ are too scattered for estimating reasonable $R_{L}$ and $L$ values, and higher frequency data points do not contain sufficient $R_{L}$ and $L$ information. Therefore, in this study only $R_{f}, R_{a}, C_{f}$ and Ca are estimated and presented in Figure 2(c) (d). 
The estimated $R_{s}$ is relatively constant, not significantly influenced by evolved hydrogen even at high potentials (Figure $2(\mathrm{~d}))$. From OCP $(\sim-1.5 \mathrm{~V} / \mathrm{SCE})$ to $\sim-$ $0.9 \mathrm{~V} / \mathrm{SCE}, \mathrm{R}_{\mathrm{f}}$ decreases continuously with increasing potential, while $\mathrm{C}_{\mathrm{f}}$ does not vary noticeably (Figure $2(\mathrm{c})$ and (d)). The decreasing $\mathrm{R}_{\mathrm{f}}$ implies that the film becomes more porous. An increase in $\mathrm{C}_{\mathrm{f}}$ as a result of higher film porosity has not been observed. This could be due to the fact that the film becomes thicker with increasing potential, which offsets the $\mathrm{C}_{\mathrm{f}}$ increase caused by the higher film porosity. Similar variations in $\mathrm{R}_{\mathrm{a}}$ and $\mathrm{C}_{\mathrm{a}}$ with increasing potential are also observed in this potential range (Figure 2(c) and (d)). The decreased $R_{a}$ may be ascribed to a larger substrate $\mathrm{Mg}$ surface area exposed to the solution in film pores (in nano micro scale) when the film becomes more porous at a higher potential. A complicated mechanism may be involved in the relatively constant $C_{a}$ behavior in the potential range, which will not be discussed in this paper.

These surface electrochemical parameters, particularly the resistances, become extremely scattered at potentials above $-0.8 \mathrm{~V} / \mathrm{SCE}$ (Figure 2(c) (d)), suggesting that a different process starts to influence the surface film microstructure, which will be further discussed later.

\subsection{Surface films under anodic polarization}


In-situ and ex-situ observations during and after immersion by naked eye showed that dark corroding areas spread over the Mg surface, the spreading rate increased with increasing potential, and hydrogen evolved mainly from the dark corroding areas. These observations are in consistence with the reported anodic hydrogen evolution [33]. The whole Mg surface was corroded and became dark within 24 hours of immersion at $-1 \mathrm{~V} / \mathrm{SCE}$. It should be noted that the anodic current densities around $-1 \mathrm{~V} / \mathrm{SCE}$ and $\mathrm{E}_{\mathrm{ip}}(\sim-0.85 \mathrm{~V} / \mathrm{SCE})$ are a few hundred microamperes and continuously increase with potential; thus the Mg electrode is not in a passive state. At more positive potentials (e.g. $\mathrm{E}>\mathrm{E}_{\mathrm{ip}}$ ), the whole surface was completely corroded and darkened in a few hours. These observations suggest that the enhanced hydrogen evolution on $\mathrm{Mg}$ at a high anodic potential in this study is unlikely to be a result of the spread of cathodically active corroding surface area [41], as the dark corroded surface area cannot further enlarge with increasing potential after the whole surface has been corroded. Moreover, at potentials more positive than $E_{i p}$, some small pieces of dark debris peeling off from the corroding Mg surface were visualized. This indicates that the anodic surface film ruptured at high potentials, which could be caused by significantly intensified hydrogen evolution (see Figure 1 (b) and (c)). If the hydrogen evolution at the high potentials is a cathodic reaction, its rate should decrease unless the active surface area for hydrogen reaction became significantly larger with increasing potential, because cathodic hydrogen evolution intensity on unit surface area always decreases with increasing potential. In a film crack, the exposed surface area of the substrate metallic Mg is very limited and cannot increase remarkably with increasing potential. Therefore, the hydrogen 
evolution rate in the film crack at a higher potential enhanced so evidently to rupture the film cannot be a cathodic hydrogen process.

Figure 3 presents some typical SEM/TEM images of Mg film cross-sections. Around OCP, some surface areas are insignificantly corroded, but some noticeably, and the film with cracks is about $2 \sim 3 \mu \mathrm{m}$ thick in the corroded area (Figure 3(a)). At $1 \mathrm{~V} / \mathrm{SCE}$, the film grows thicker $(\sim 10 \mu \mathrm{m})$, more uniformly over most of the surface area (Figure $3(\mathrm{~b})$ ). It then becomes loosely ruptured at $0 \mathrm{~V} / \mathrm{SCE}$, quite thick in some areas (Figure $3(\mathrm{c})$ ) and penetrating deeply into the substrate in some other locations (Figure 3(d)).

To reveal more detailed microstructure of a complete film, some local regions of thinner film were analyzed using STEM (Figure 3(e) (g)). All the films consist of a dense inner layer and a loose filamentous outer layer. The inner and outer layer thickness varies from location to location. The thick filamentous porous outer layer of the film formed on Mg at 0V/SCE (Figure 3(g)) has almost the same morphology as that on Mg alloys in salt solution [42]. This may imply that the outer layer results from deposition of supersaturated $\mathrm{Mg}^{2+}$ from solution, because $\mathrm{Mg}$ can be rapidly dissolved either in the non-corrosive solution at a high anodic potential or in a chloride-containing solution at OCP. 
Electron diffraction analyses indicate that both the inner and outer layers are a mixture of $\mathrm{MgO}+\mathrm{Mg}(\mathrm{OH})_{2}$, the inner dominated by $\mathrm{MgO}$ and the outer by $\mathrm{Mg}(\mathrm{OH})_{2}$. TEM/SEM electron beam can to some degree dehydrate or modify the $\mathrm{Mg}(\mathrm{OH})_{2}$, but a significant amount of $\mathrm{Mg}(\mathrm{OH})_{2}$ still remains after TEM observations. A typical electron diffraction pattern is shown in Figure $3(\mathrm{~h})$. The $\mathrm{MgO}+\mathrm{Mg}(\mathrm{OH})_{2}$ mixture has also been confirmed by electron-energy-loss-spectroscopy analysis, which shows both $\mathrm{MgO}$ and $\mathrm{Mg}(\mathrm{OH})_{2}$ together in the outer layer. These support the recent publications that $\mathrm{H}$ is distributed throughout the inner and outer layers $[21,22]$.

The film cracks shown in the SEM cross-sections (Figure 3(a) (d)) can also be observed in the topographic images (Figure 3(i)). Surprisingly, before SEM analysis, no crack can be visualized under the 3D confocal OM that has sufficiently high resolution to reveal film details (Figure 3(j)). This observation suggests that the original films formed at OCP and low potentials may be microcrack-free. In SEM, the $\mathrm{Mg}(\mathrm{OH})_{2}$ in the films may be dehydrated, turning into smaller mole-volume MgO, generating cracks. Such cracks would also be expected with the decrease in volume when $\mathrm{Mg}$ is directly converted to MgO. Element mapping confirms a non-uniform corrosion distribution over Mg at OCP; the area next to a severely corroded spot is lightly corroded, mainly containing metallic Mg, not its oxides. This could be due to the galvanic effect between the corroding site and its surrounding region. 
It should be noted that from all the topographic and cross-sectional SEM and STEM images obtained in this study (most of the photos are not presented here), no heavy element (e.g. Fe) rich particle can be detected in the corroded areas on Mg surfaces. There is no evidence to support that the accelerated corrosion, film formation or hydrogen evolution with increasing potential can be associated with enrichment of Fe or noble elements on Mg surface.

\subsection{Anodic surface film model and hydrogen evolution mechanism}

The above results suggest that $\mathrm{Mg}$ is covered by a $\mathrm{MgO}+\mathrm{Mg}(\mathrm{OH})_{2}$ film that has a relatively dense inner and a loose outer layers (Figure 4(a)). In fact, the presence of $\mathrm{MgO}$ and $\mathrm{Mg}(\mathrm{OH})_{2}$ in the surface films on $\mathrm{Mg}$ and its alloy in water has been confirmed by XPS analysis $[11,22]$. It can be reasonably assumed that the $\mathrm{Mg}(\mathrm{OH})_{2}$ concentration in the film decreases and $\mathrm{MgO}$ content increases with film depth. All the film pores are filled with saturated $\mathrm{Mg}(\mathrm{OH})_{2}$ solution. An enlarged section of the film is schematically illustrated in Figure 4(b).

Reaction $\mathrm{Mg}+\mathrm{O}^{2-} \rightarrow \mathrm{MgO}+2 \mathrm{e}^{-}$occurs at the interface between the inner layer and $\mathrm{Mg}$, while $\mathrm{Mg}+2 \mathrm{H}_{2} \mathrm{O} \rightarrow \mathrm{Mg}^{2+}+2 \mathrm{OH}^{-}+\mathrm{H}_{2}+2 \mathrm{e}^{-}$proceeds on the $\mathrm{Mg}$ surface exposed to the solution in film pores/cracks (Figure 4(b)). The inner layer grows when $\mathrm{Mg}$ is oxidized by inward oxygen transport [22]. The outer develops by Mg dissolution (outward) from the substrate into pore solution and then $\mathrm{Mg}(\mathrm{OH})_{2}$ deposition from 
the pore solution. The $\mathrm{Mg}(\mathrm{OH})_{2}$ and $\mathrm{MgO}$ in the inner and outer layers may convert each other through $\mathrm{MgO}+\mathrm{H}_{2} \mathrm{O}=\mathrm{Mg}(\mathrm{OH})_{2}$, depending on the water content in the layers. Increasing potential can accelerate the Mg oxidation, dissolution, and thus $\mathrm{Mg}(\mathrm{OH})_{2}$ deposition, resulting in a thickened film.

No cathodic hydrogen evolution in theory can occur on bare metallic Mg surface at a potential more positive than the hydrogen equilibrium potential $\left(\sim-0.60 \mathrm{~V}_{\text {true }} / \mathrm{SHE}\right)$. The presence of an oxide/hydroxide film on Mg will make the cathodic hydrogen evolution at the same potential even more difficult. This is because the oxide/hydroxide film is not a good electronic conductor and cannot easily conduct electrons, and the probability of electron transmission from the substrate $\mathrm{Mg}$ through the film to the film surface is extremely low. Furthermore, the electric field across the film, which drives a high anodic current density from the substrate $\mathrm{Mg}$ through the film to the solution, is against the direction of electron travelling from the substrate $\mathrm{Mg}$ to the film surface. Thereby, it is unlikely for the cathodic hydrogen evolution to occur on the film surface as described in the catalytic surface mechanism [17]. All these suggest that cathodic hydrogen evolution should take place on the substrate metallic Mg exposed to the solution in film pores at the $\mathrm{Mg} /$ film (M/F) interface.

Based on the above analyses, the model $[33,43,44]$ that combines the partially protective film and the $\mathrm{Mg}^{+}$involved in $\mathrm{Mg}$ dissolution offers a reasonable 
explanation for the hydrogen evolution at anodic potentials (Figure 1 (b) and (c)). In this model, the hydrogen evolution at high anodic potentials is not a cathodic reaction, but mainly a result of anodic dissolution of $\mathrm{Mg}^{+}$and immediate chemical reaction of the dissolved $\mathrm{Mg}^{+}$with water on the substrate $\mathrm{Mg}$ surface exposed to the solution in film pores [33]; limited cathodic hydrogen evolution may also occur on the substrate Mg surface, but its intensity decreases with increasing potential [7]. In fact, it has been in-situ visualized under a microscope that the hydrogen evolution directly from corroding areas always follows corrosion development (i.e., hydrogen bubbles come out from the forefront of corroding region) on an Mg alloy surface under anodic polarization, and it ceases by cathodic polarization $[44,45]$. Under a cathodic polarization, hydrogen evolves from some particular sites on a Mg alloy surface, and the reaction noticeably slows down and even completely stops as polarization potential anodically shifts. This is obviously a normal cathodic hydrogen evolution reaction (CHE). No corrosion damage can be observed on these cathodic sites for CHE. However, on other areas where severe corrosion is occurring, intense hydrogen evolution can be observed, and the hydrogen reaction dramatically intensifies while the polarization potential is becoming more positive. This hydrogen evolution process is clearly an anodic reaction (i,e., anodic hydrogen evolution, AHE). If the electrode is cathodically polarized again, the ACE slows down and stops in the corroded area, whereas CHE is triggered again from those cathodic sites $[44,45]$. These observations suggested that the hydrogen evolution in a corroding area mainly results from an anodic process (i.e. AHE). 
If the hydrogen evolution from the corroding area is ascribed to a cathodic hydrogen reaction on the corrosion product film, and the increasing hydrogen evolution rate with increasing potential is attributed to enlarged corroding areas or enrichment of impurity on the Mg surface, then the Negative Difference Effect (NDE) of Mg in strong acidic solutions (i.e., hydrogen evolution rate increasing with increasing potential in acidic solutions) [43] cannot be explained. In the strong acidic solutions, the whole Mg surface is film-free, and thus the corroding area cannot become larger with increasing potential. In this case, no corrosion product can stay on the Mg surface due to the rapid uniform dissolution of $\mathrm{Mg}$, and consequently impurity enrichment cannot occur, either. Therefore, CHE should decrease with increasing potential, and there should be no NDE if AHE is not considered.

According to this model of $\mathrm{Mg}^{+}$involved in $\mathrm{Mg}$ dissolution in film-broken areas, under anodic polarization Mg surface and hydrogen evolution are activated by $\mathrm{Mg}^{+}$. Such an intermediate product of Mg anodic dissolution has extremely short-life and may exist only on the substrate metallic Mg surface under the film pores for a very short period of time. It cannot be easily detected by conventional chemical analysis, ICP or Raman spectroscopy that only detects species on film surface or in bulk solution $[35,36]$. Although the presence of $\mathrm{Mg}^{+}$has not yet been experimentally confirmed, the mechanism of $\mathrm{Mg}^{+}$involved in $\mathrm{Mg}$ dissolution in film-broken areas $[33,43,44]$ can very well explain many experimental results so far. 
In the model, the AHE takes place on substrate Mg surface exposed the solution in the film pores (at the M/F interface) through [7]:

$$
\begin{aligned}
& \mathrm{Mg} \rightarrow \mathrm{Mg}^{+}+\mathrm{e}^{-} \\
& \mathrm{Mg}^{+}+\mathrm{H}_{2} \mathrm{O} \rightarrow \mathrm{Mg}^{2+}+1 / 2 \mathrm{OH}^{-}+1 / 2 \mathrm{H}_{2}
\end{aligned}
$$

The single-electron electrochemical reaction (1) is easier than a multi-electron process, and the chemical reaction (2) of $\mathrm{Mg}^{+}$with water can be completed within micro-seconds [46,47], resulting in AHE. Reaction (1) is accelerated by increasing potential, which facilitates reaction (2). Therefore, AHE rate increases with increasing potential, even when potential is more positive than 0V/SCE (Figure 1(b) (c)) or the potential at the film-covered Mg surface is close to the equilibrium hydrogen potential.

As the involvement of $\mathrm{Mg}^{+}$in $\mathrm{Mg}$ dissolution can yield a capacitive EIS loop at intermediate or low frequencies [43], and the porous/cracked surface film can generate another capacitive loop at high frequencies [43], EISs will exhibit two capacitive loops as shown in Figure 2(a).

Around OCP, surface micro-galvanic cells dominate the corrosion (Figure 4(c)). A severely corroding site can galvanically protect its surrounding region. Thus, the corrosion damage is non-uniform, and the film thickness varies widely (Figure 3(a)). 
When an anodic potential e.g., $-1 \mathrm{~V} / \mathrm{SCE}$, is applied, Mg dissolution over the entire surface will be driven uniformly by the applied voltage (Figure 4(d)). Hence, the film becomes thicker and more uniform (Figure 3(b)). If a high potential above a critical value (e.g., 0V/SCE) is applied (Figure 4(e)), the AHE will be dramatically enhanced (Figure 1(b) (c)). The rapidly generated hydrogen may be trapped/accumulated in the film pores, which may rupture the film (Figure 3(c)). Thereby, the film becomes more porous and cracked, and current densities noticeably increase when potential is higher than the critical value (Figure 1(a)). The film rupture caused by the accelerated AHE at a high potential differs from the chloride-induced film damage $[21,22,42]$.

The trapped hydrogen bubbles may block and unblock the liquid/current paths in the film, resulting in unstable currents and thus scattered electrochemical surface parameters (Figure 2(b) (c)). Some generated $\mathrm{H}$ atoms from reaction (2) may diffuse into the Mg substrate through some metallurgical defects [21]. The $\mathrm{H}$ ingress zones may act as shortcuts for corrosion, resulting in deeply penetrated corrosion patterns (Figure 3(d)).

Based on the above discussion, $\mathrm{Mg}$ should be dissolved first as $\mathrm{Mg}^{+}$and then $\mathrm{Mg}^{2+}$ in film-broken areas on Mg surface, and at the same time hydrogen is generated in these film-free regions. The poor corrosion performance of $\mathrm{Mg}$ is basically due to the porous nature of the film formed on $\mathrm{Mg}$. The film porosity increases with 
increasing potential, particularly when $\mathrm{Mg}$ is polarized more anodically than $\mathrm{E}_{\mathrm{ip}}$. It should be noted that although the model of $\mathrm{Mg}^{+}$involved in $\mathrm{Mg}$ dissolution in film broken areas has successfully explained many experiment results so far, there is a lack of in-situ experimental evidence to directly prove the existence of the extremely short life-span intermediate $\mathrm{Mg}^{+}$ions on $\mathrm{Mg}$ surface in solutions. Another ambiguous point in this model is the separation of CHE from AHE in experiment. According to this model, the CHE from the substrate Mg exposed to solution in film pores cannot be excluded [40]. Although this CHE process in theory cannot result in a NDE phenomenon, the hydrogen bubbles from the CHE actually mixes together with those from the AHE during hydrogen evolution measurement. Because of the difficulty in distinguishing AHE and CHE, different models are proposed to interpret the experimentally collected hydrogen. It is expected that the advancement of modern experimental techniques will eventually help clarify these ambiguous points.

\section{Conclusions}

1. The hydrogen evolution becomes more intensive when the potential at the film-covered Mg surface is more positive than the hydrogen equilibrium potential. This mainly results from the "anodic hydrogen evolution" on the substrate metallic Mg surface exposed to the solution in film pores. 
2. The film on $\mathrm{Mg}$ is not composed of a pure $\mathrm{Mg}(\mathrm{OH})_{2}$ layer over a pure $\mathrm{MgO}$ layer. Its relatively dense inner layer and loose outer layer both consist of a mixture of $\mathrm{MgO}$ and $\mathrm{Mg}(\mathrm{OH})_{2}$. The inner layer is dominated by $\mathrm{MgO}$ and the outer mainly $\mathrm{Mg}(\mathrm{OH})_{2}$. Cracking in the film was observed, which may be a result of film dehydration during SEM/TEM analysis in vacuum.

3. The film formed at a higher anodic potential still has a double-layer structure. It becomes thicker, but less resistant due to the increased film porosity at the higher anodic potential.

4. The film can rupture in non-corrosive $\mathrm{Mg}(\mathrm{OH})_{2}$ solution when anodic potential is more positive than a critical value. This kind of film damage can be attributed to the dramatically intensified anodic hydrogen evolution in the film pores.

\section{Acknowledgements}

The research was sponsored by the Laboratory Directed Research and Development Program of Oak Ridge National Laboratory. This manuscript has been authored by UT-Battelle, LLC, under Contract No. DE-AC05-000R22725 with the U.S. Department of Energy. The United States Government retains and the publisher, by accepting the article for publication, acknowledges that the United States Government retains a non-exclusive, paid-up, irrevocable, world-wide license to publish or reproduce the published form of this manuscript, or allow others to do so, for United States 
Government purposes. Dr. M. P. Brady's beneficial discussion, Ms. T. Lowe's help in SEM and Ms. S. Curlin's assistance in optical microscopy are appreciated. 


\section{Figure captions}

Figure 1. Polarization curves and hydrogen evolution results for $\mathrm{Mg}$ in saturated $\mathrm{Mg}(\mathrm{OH})_{2}$ solution:

(a) experimental and IR-corrected potentiostatic polarization curves,

(b) average hydrogen evolution rates at different potentials, and

(c) hydrogen evolution volume vs. time.

Figure 2. EIS results for $\mathrm{Mg}$ in saturated $\mathrm{Mg}(\mathrm{OH})_{2}$ solution:

(a) experimentally measured typical EISs at different potentials and fitted EISs using the equivalent circuit shown in (b),

(b) equivalent circuit used to estimate the electrochemical parameters of the film-covered Mg,

(c) estimated capacitances $\mathrm{C}_{\mathrm{f}}$ and $\mathrm{C}_{\mathrm{a}}$, and

(d) estimated resistances $R_{\mathrm{s}}, \mathrm{R}_{\mathrm{f}}$ and $\mathrm{R}_{\mathrm{a}}$.

* It should be noted that in (c) and (d), value $10^{20}$ is used to represent $\infty$ in curvefitting for estimation of the resistance and capacitance values.

Figure 3. Anodically polarized surfaces and films of Mg after immersion in saturated $\mathrm{Mg}(\mathrm{OH})_{2}$ solution at different potentials for 24 hours:

(a) BSE SEM cross-section image of a Mg surface region after immersion at OCP,

(b) BSE SEM cross-section image of a Mg surface region after immersion at $1 \mathrm{~V} / \mathrm{SCE}$,

(c) BSE SEM cross-section image of a Mg surface region after immersion at OV/SCE,

(d) BSE SEM cross-section image of a different surface region after immersion at OV/SCE,

(e) HAADF STEM cross-section image of a Mg surface region after immersion at OCP,

(f) HAADF STEM cross-section image of a Mg surface region after immersion at $1 \mathrm{~V} / \mathrm{SCE}$,

(g) HAADF STEM cross-section image of a Mg surface region after immersion at OV/SCE,

(h) a typical electron diffraction pattern obtained from the outer of the film formed on Mg at OCP,

(i) a typical SEM topographic image of the film formed on $\mathrm{Mg}$, and

(j) a typical confocal optical microscopic image of the film formed on $\mathrm{Mg}$ before SEM examination.

Figure 4. Schematic illustration of anodic surface film and hydrogen evolution:

(a) a micro-view of the surface film on $\mathrm{Mg}$,

(b) the enlarged micro-view of the section shown in (a), and the reactions involved in the film formation and dissolution,

(c) current distribution and macro-view of the film formed on Mg around OCP 
(d) current distribution and macro-view of the film formed on Mg at an anodic potential, e.g., $-1 \mathrm{~V} / \mathrm{SCE}$

(e) current distribution and macro-view of the film structure on Mg at a very positive potential, e.g., $0 \mathrm{~V} / \mathrm{SCE}$ 


\section{References}

[1] G.-L. Song, Preface, in G.-L. Song (ed.), Corrosion of Magnesium alloys, Woodhead Publishing Limited, UK, 2011

[2] F.Witte, V.Kaese, H.Haferkamp, E.Switzer, A.Meyer-Lindenberg, C.J.Wirth, H.Windhagen, In-vivo corrosion of four magnesium alloys and the associated bone response, Biomaterials 26 (2005) 3557-3563.

[3] G.G. Perrault, Magneium, in A.J.Bard (ed.), Encyclopedia of electrochemistry of the elements, Marcel Dekker (1978) pp.263-319.

[4] G.G.Perrault, The potential-pH diagram of the magnesium-water system, Electroanalytical Chemical an Interfacial Electrochemistry 51(1974) 107-119.

[5] G.L.Makar, J.Kruger, Corrosion of magnesium, International Materials Reviews 38 (1993) 138-153.

[6] G.-L. Song, Z. Xu, Crystal Orientation and Electrochemical Corrosion of Polycrystalline Mg, Corrosion Science 63(2012) 100-112.

[7] G.-L. Song, Chapter 1:Electrochemistry of Mg and its Alloys, in G.-L. Song (ed.), Corrosion of Magnesium alloys, Woodhead publishing Limited, UK, 2011, pp.3-65

[8] S.J. Splinter, N.S McIntyre, The initial interaction of water vapour with Mg-Al alloy surfaces at room temperature, Surface Science 314 (1994) 157-171.

[9] S. Feliu Jr. C. Maffiotte, A. Samaniego, J. C. Galván, V. Barranco, Effect of the chemistry and structure of the native oxide surface film on the corrosion properties of commercial AZ31 and AZ61 alloys, Applied Surface Science 257 (2011) 85588568.

[10] J. Liao, M. Hotta, S. Motoda, T. Shinohara, Atmospheric corrosion of two fieldexposed AZ31B magnesium alloys with different grain size, Corrosion Science 71 (2013) 53-61.

[11] G.-L. Song, M. Liu, The Effect of Surface Pretreatment on the Corrosion Performance of Electroless E-Coating Coated AZ31, Corrosion Science 62 (2012) 61-72.

[12] A. Seyeux, M.Liu, P. Schmutz, G.-L. Song, A. Atrens, P. Marcus, ToF-SIMS depth profile of the surface film on pure magnesium formed by immersion in pure water and the identification of magnesium hydroxide, Corrosion Science 51 (2009) 18831886.

[13] J. H. Nordlien, S. One, and N.Masuko, Morphology and structure of oxide films formed on magnesium by exposure to air and water, Journal of the Electrochemical Society 142 (1995) 3320-3322.

[14] C. S. Lin, and Y. C. Fu, Characterization of anodic films on AZ31 magnesium alloys in alkaline solutions containing fluoride and phosphate anions, Journal of the Electrochemical Society 153 (2006) B417-B424.

[15] P. C. Howlett, J. Efthimiadis, P. Hale, G. A. van Riessen, D. R. MacFarlane, and 
M. Forsyth, Characterization of the magnesium alloy AZ31 surface in the ionic liquid trihexyl(tetradecyl)phosphonium bis(trifluoromethanesulfonyl)amide, Journal of The Electrochemical Society 157 (2010) C392-C398.

[16] M. Taheri, and J. R. Kish, Nature of surface film formed on Mg exposed to $1 \mathrm{M}$ $\mathrm{NaOH}$, Journal of the Electrochemical Society 160 (2013) C36-C41.

[17] M.Taheri, J.R.Kish, N.Birbilis, M.Danaie, E.A.McNally, J.R.McDermid, Towards a physical description for the origin of enhanced catalytic activity of corroding magnesium surfaces Electrochimica Acta 116 (2014) 396-403.

[18] R.C. Phillips and J.R. Kish, Nature of surface film on matrix phase of $\mathrm{Mg}$ alloy AZ80 formed in water, Corrosion 69 (2013) 813-820.

[19] M. Taheri, R.C. Phillips, J.R. Kish, G.A. Botton, Analysis of the surface film formed on $\mathrm{Mg}$ by exposure to water using a FIB cross-section and STEM-EDS, Corrosion Science 59 (2012) 222-228.

[20] M. Jonsson, D. Persso, D. Thierry, Corrosion product formation during $\mathrm{NaCl}$ induced atmospheric corrosion of magnesium alloy AZ91D, Corrosion Science 49 (2007) 1540-1558.

[21] M.P. Brady, M.Fayek, H.H. Elsentriecy, K.A. Unocic, L.M.Anovitz, J.R.Keiser, G.L. Song, B. Davis, Tracer film growth study of hydrogen and oxygen from the corrosion of magnesium in water, Journal of the Electrochemical Society 161(9) (2014) C395-C404.

[22] K.A. Unocic, H.H. Elsentriecy, M.P. Brady, H.M. Meyer, G.-L. Song, M. Fayek, R.A. Meisner, B. Davis, Transmission electron microscopy study of aqueous film formation and evolution on magnesium alloys, Journal of the Electrochemical Society 161(6) (2014) C302-C311.

[23] M.P.Staiger, A.M.Pietak, J.Huadmai, G.Dias, Magnesium and its alloys as orthopaedic biomaterials: A review, Biomaterials 27 (2006) 1728-1734.

[24] M.Tomozawa, S.Hiromoto, Growth mechanism of hydroxyapatite-coatings formed on pure magnesium and corrosion behaviour of the coated magnesium, Applied Surface Science 257 (2011) 8253-8257.

[25] L.Xu, F.Pan, G.Yu, L.Yang, E.Zhang, K.Yang, In vitro and in vivo evaluation of the surface bioactivity of a calcium phosphate coated magnesium alloy, Biomaterials 30 (2009)1512-1523.

[26] Z. Li, G.-L.Song, S.Song, Effect of Bicarbonate on Biodegradation behaviour of pure magnesium in a simulated body fluid, Electrochimica Acta 115 (2014) 56-65.

[27] P.L.Bonora, M.Andrei, A.Eliezer, E.M.Guatman, Corrosion behaviour of stressed magnesium alloys, Corrosion Science 44(2002)729-749.

[28] Y.Song, D.Shan, R.Chen, E.H.Han, Effect of second phases on the corrosion behavior of wrought Mg-Zn-Y-Zr alloy, Corrosion Science 52(2010)1830-1837 
[29] E.Ghali, Chapter 2: Activity and passivity of Magnesium (Mg) and its Alloys, in G.-L. Song (ed.), Corrosion of Magnesium alloys, Woodhead publishing Limited, UK, 2011, pp.66-114

[30] G.-L. Song, Effect of tin modification on corrosion of AM70 magnesium alloy, Corrosion Science 51 (2009) 2063-2070.

[31] Y.Choi, S.Salman, K.Kuroda, M.Okido, Improvement in corrosion characteristics of AZ31 Mg alloy by square pulse anodizing between transpassive and active regions, Corrosion Science 63 (2012) 5-11.

[32] S.Moon, Y.Nam, Anodic oxidation of $\mathrm{Mg}-\mathrm{Sn}$ alloys in alkaline solutions, Corrosion Science 65 (2012) 494 -501.

[33] G. Song, Recent progress in corrosion and protection of magnesium alloys, Advanced Engineering Materials 7 (2005)563-586.

[34] G.S.Frankel, A.Samaniego, N.Birbilis, Evolution of hydrogen at dissolving magnesium surfaces, Corrosion Science 70 (2013) 104-111.

[35] A.Samaniego, B.Hurley, G.S.Frankel, On the evidence for univalent Mg, Journal of Electroanalytical Chemistry, Doi 10.1016/j.jelechem.2014.04.013.

[36] L.Rossrucker, K.J.J.Mayrhofer, G.S.Frankel, N.Birbilis, Investigating the real time dissolution of Mg using online analysis by ICP-MS, Journal of the Electrochemical Society 161 (2014) C115-C119.

[37] G.-L. Song, Potential and current distributions of one-dimensional galvanic corrosion systems, Corrosion Science 52 (2010) 455-480.

[38] G.-L. Song, N. Dudney, J. Li, R. Sacci, J. Thomson, The possibility of forming a sacrificial anode coating for Mg, Corrosion Science 87 (2014) 11-14.

[39] G.-L. Song, Z. Shi, Corrosion mechanism and evaluation of anodized magnesium alloys, Corrosion Science 85 (2014) 126-140.

[40] G.Song, A.Atrens, D.StJohn, J.Nairn and Y.Li, The Electrochemical corrosion of pure Magnesium in $1 \mathrm{~N} \mathrm{NaCl}$, Corrosion Science 39 (1997) 855-875.

[41] M. Curioni, The behaviour of magnesium during free corrosion and potentiodynamic polarization investigated by real-time hydrogen measurement and optical imaging, Electrochimica Acta 120(2014)284292.

[42] M.Brady, G.Rother, L.Anovitz, K.Littrell, K.Unocic, H.Elsentriecy, G.-L.Song, J.Thomson, N.Gallego, B.Davis, Film breakdown and nano-porous $\mathrm{Mg}(\mathrm{OH})_{2}$ formation from corrosion of magnesium alloys in salt solutions, Journal of the Electrochemical Society 162 (4) (2015) C140-C149

[43] G. Song, A. Atrens, D.StJohn, X. Wu, and J. Nairn, The Anodic dissolution of magnesium in chloride and sulphate solutions, Corrosion Science 39 (1997) 19812004. 
[44] G. Song, A. Atrens, Corrosion mechanisms of magnesium alloys, Advanced Engineering Materials 1 (1999) 11-33.

[45] G. Song, D. StJohn, The effect of zirconium grain refinement on the corrosion behaviour of magnesium-rare earth alloy MEZ, Journal of Light Metals 2 (2002) 116.

[46] A.C. Harms, S.N. Khanna, B. Chen, A.W. Castleman Jr., Dehydrogenation reactions in $\mathrm{Mg}^{+}(\mathrm{H} 2 \mathrm{O})_{\mathrm{n}}$ clusters, J. Chem. Phys. 100 (1994) 3540-3544.

[47] F. Missizu, M. Sanekata, K. Tsukamoto, K. Fuke, Photodissociation of size-selected $\mathrm{Mg}^{+}(\mathrm{H} 2 \mathrm{O})_{\mathrm{n}}$ ions for $\mathrm{n}=1$ and 2, J. Phys. Chem. 96 (1992) 8259-8264. 

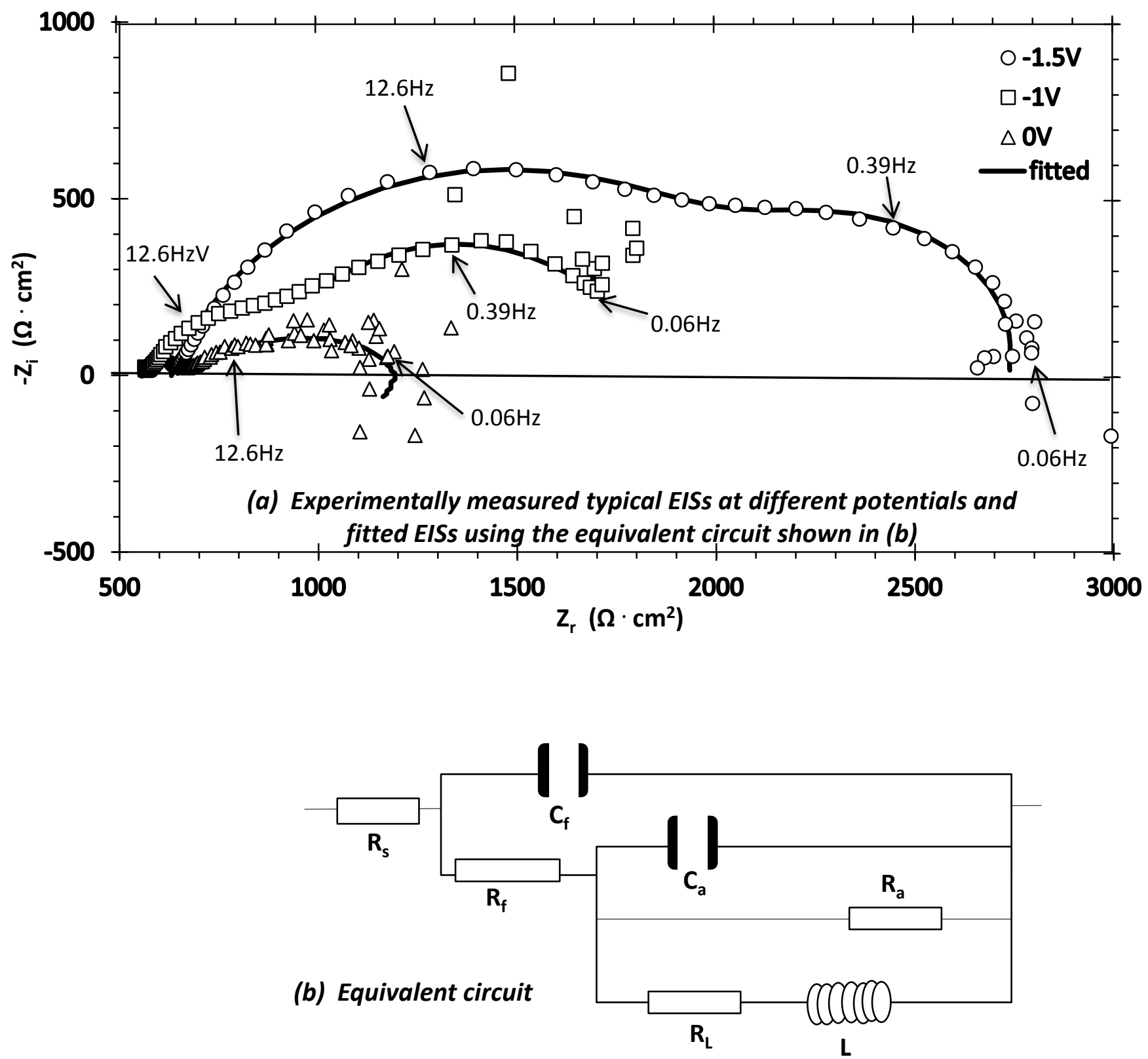


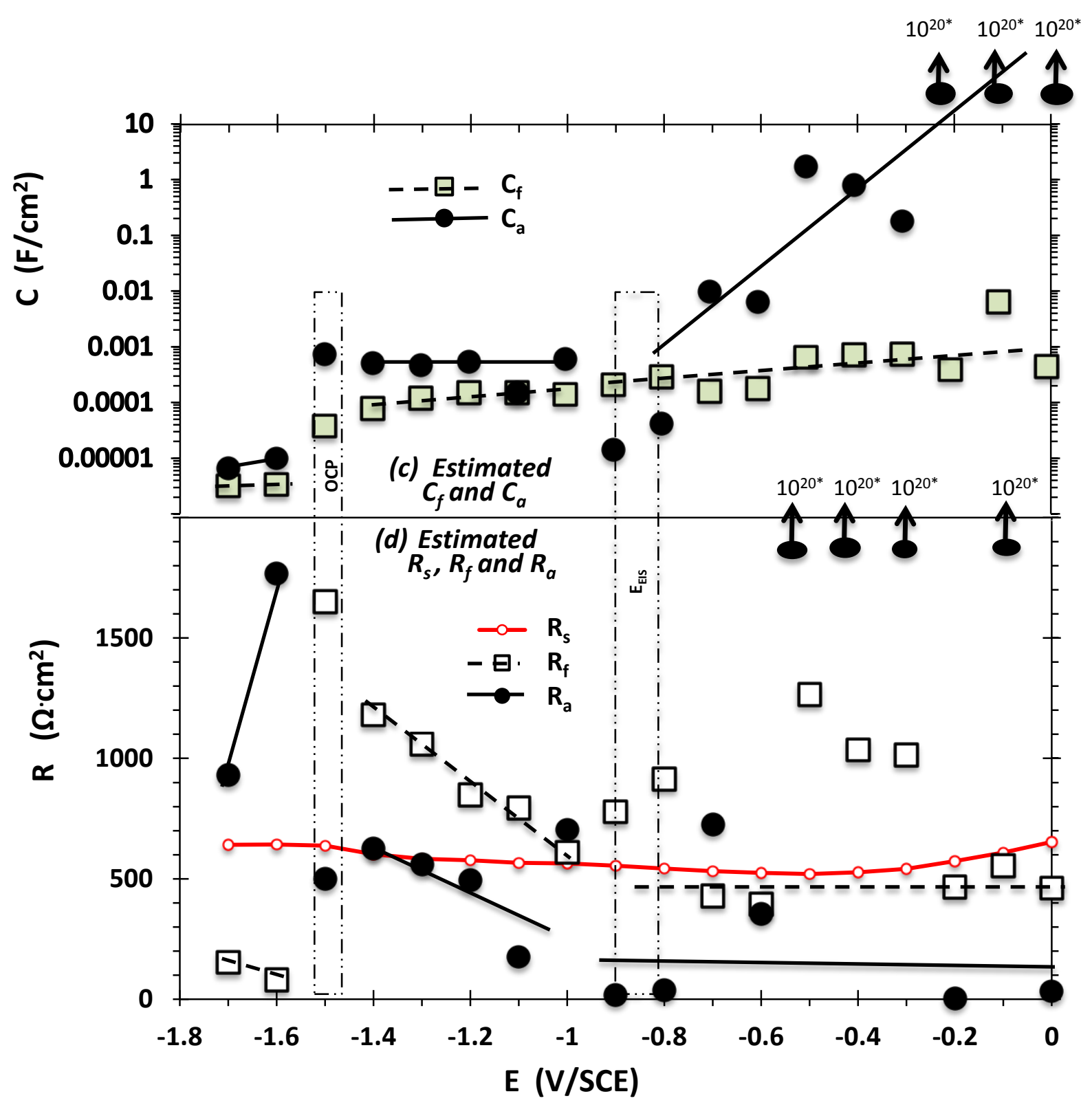

Fig.2. EIS results 


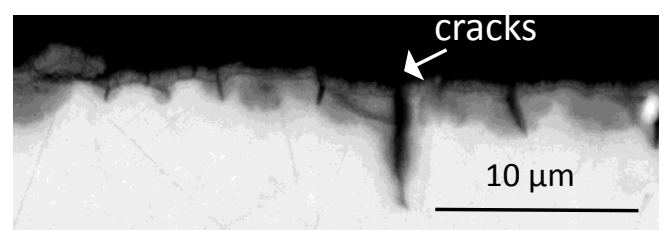

(a) BSE SEM, OCP

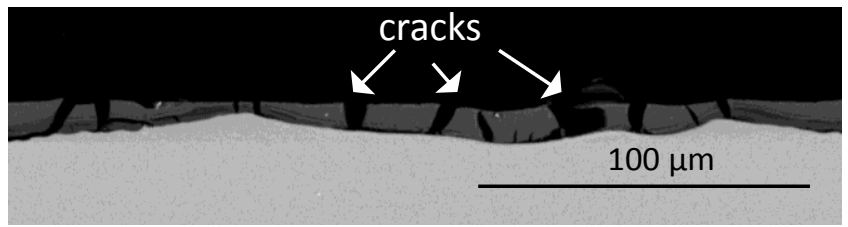

(b) BSE SEM, -1 V/SCE

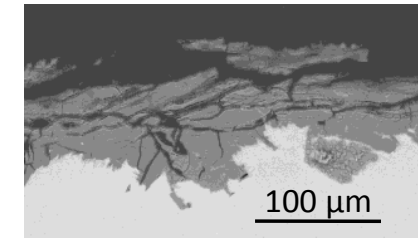

(c) BSE SEM, 0 V/SCE

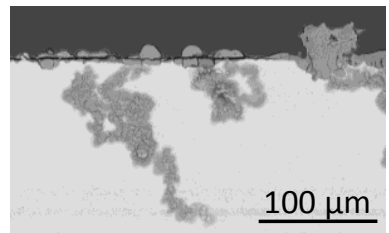

(d) BSE SEM. 0 V/SCE

\section{Fig.3. Anodically polarized Surfaces and films}




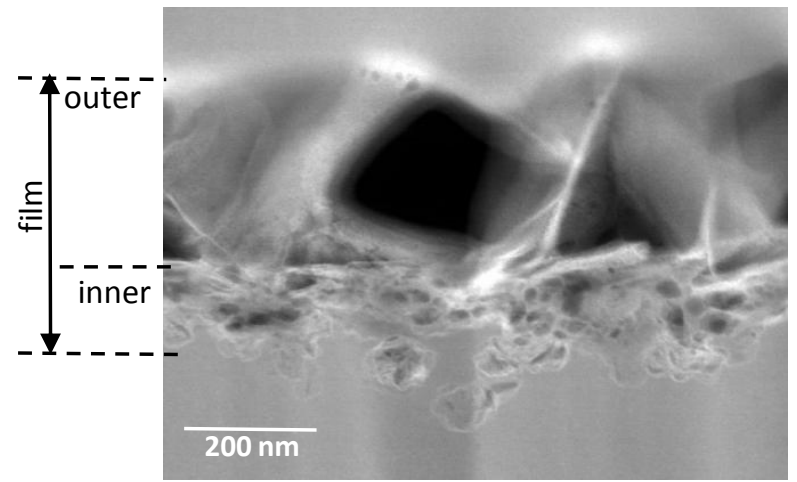

(e) HAADF STEM, OCP

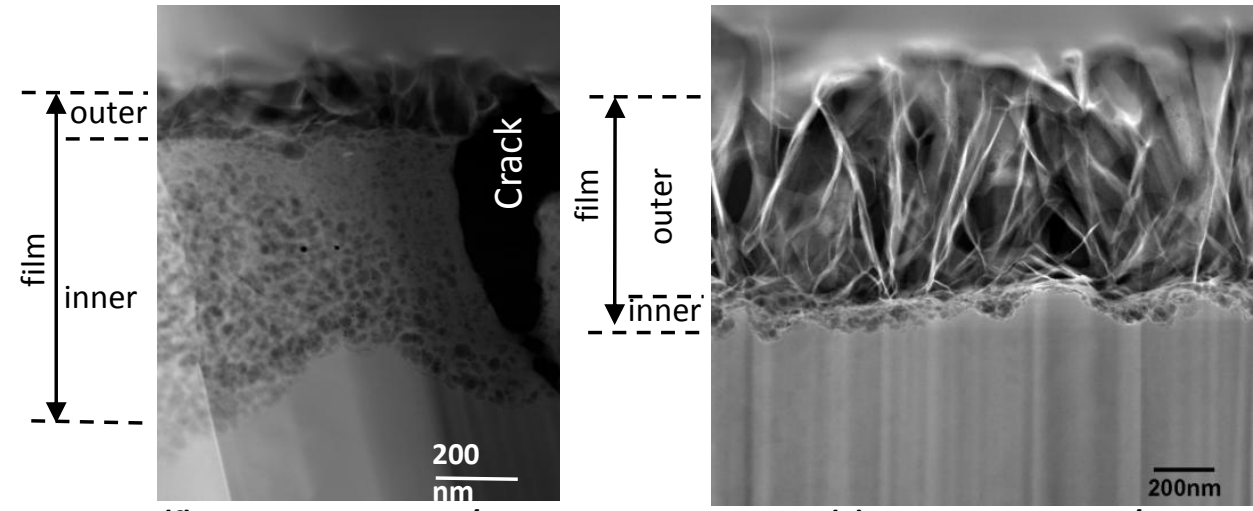

(f) HAADF STEM, -1 V/SCE

(g) HAADF STEM, 0 V/SCE

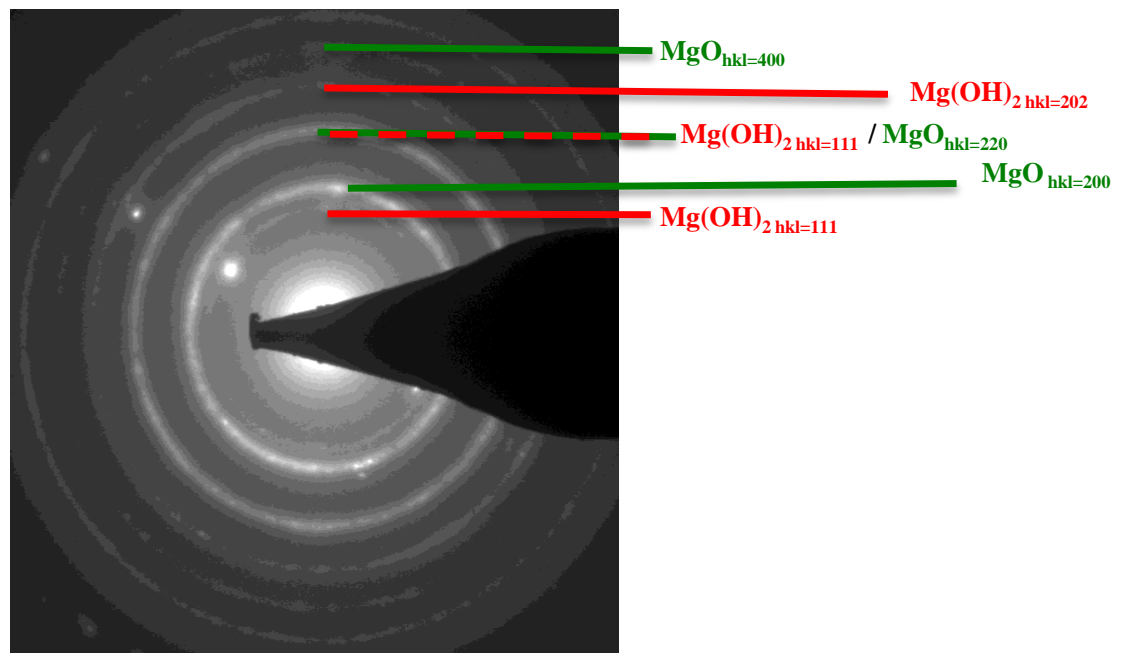

(h) Electron diffraction pattern

Fig.3. Anodically polarized Surfaces and films 

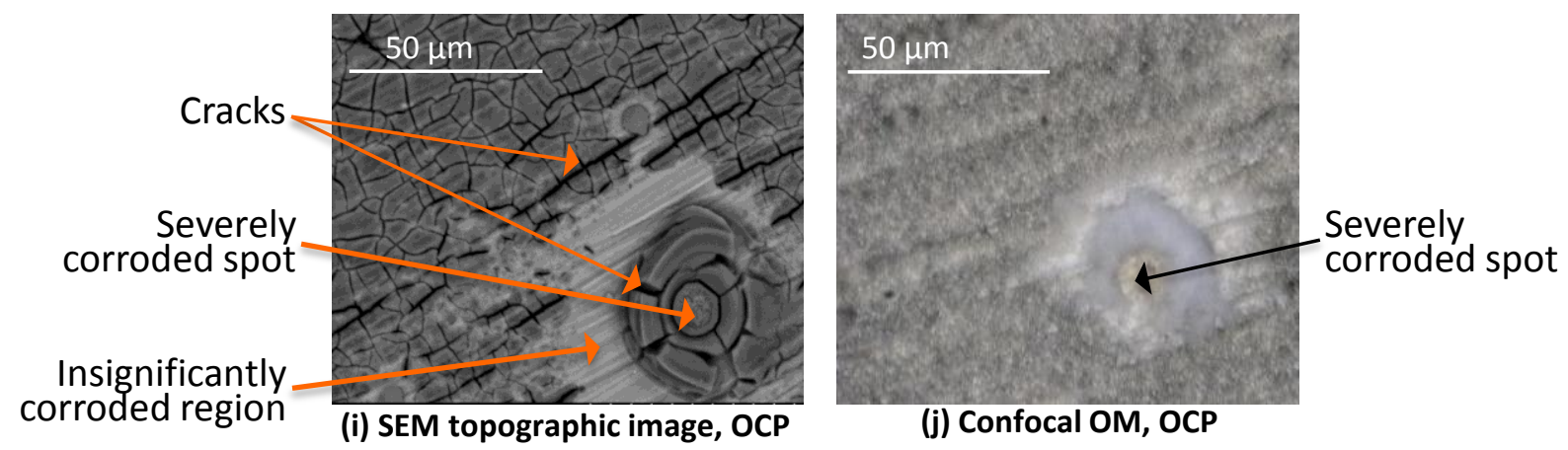

\section{Fig.3. Anodically polarized Surfaces and films}




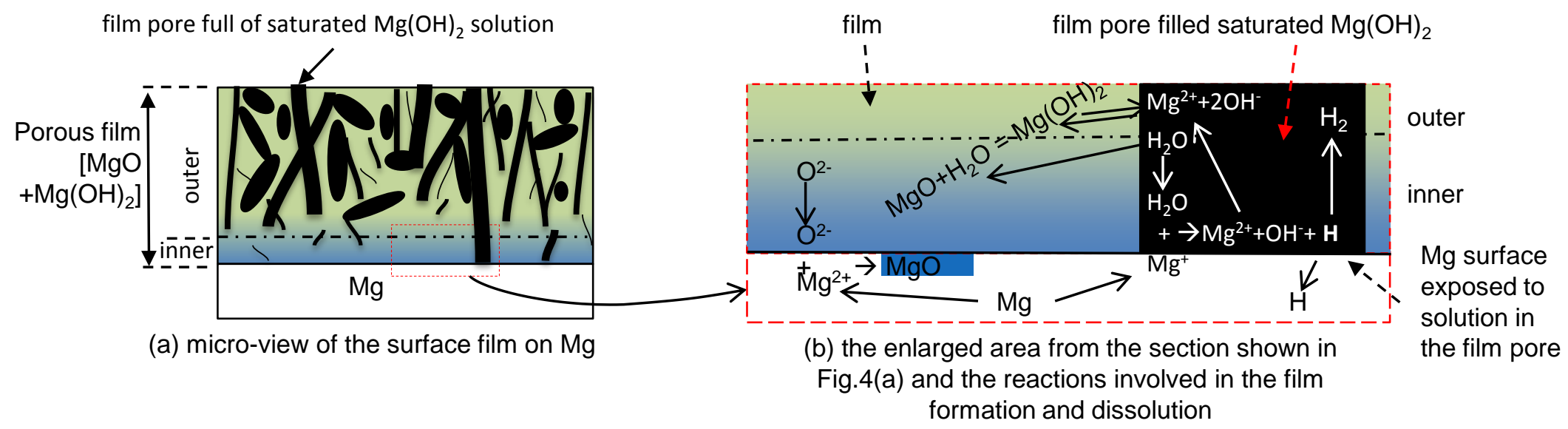




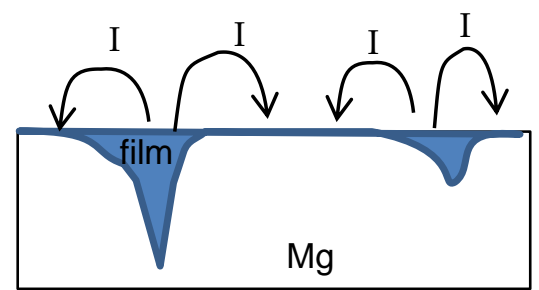

(c) current distribution and macro-view of the film formed on $\mathrm{Mg}$ around OCP

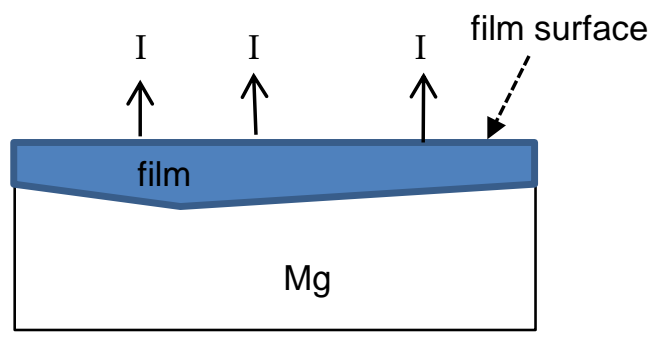

(d) current distribution and macroview of the film formed on $\mathrm{Mg}$ at an anodic potential, e.g., -1V/SCE

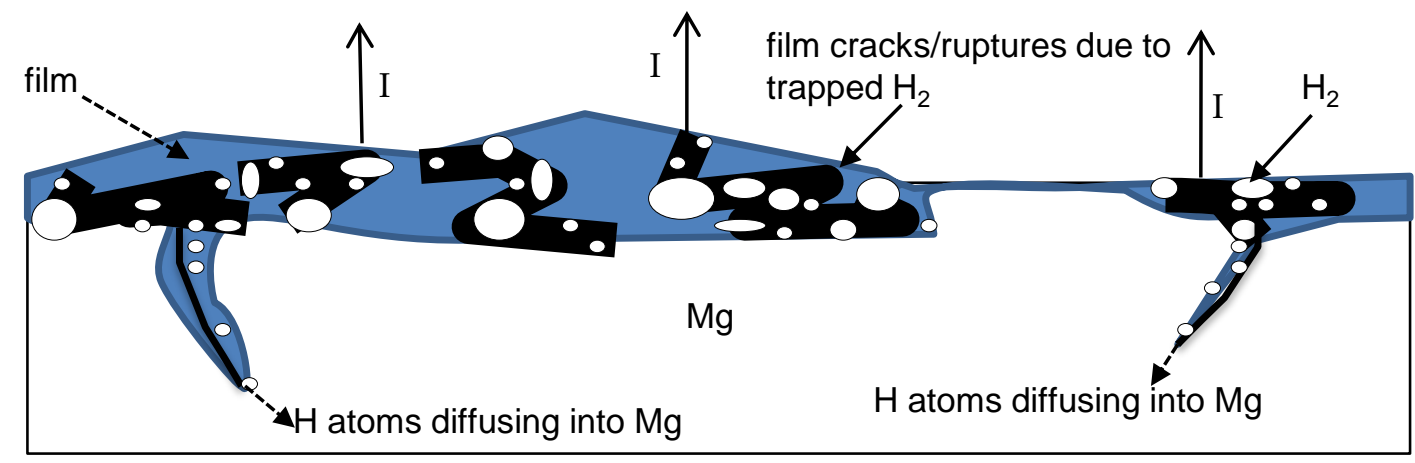

(e) current distribution and macro-view of the film structure on Mg at a very positive potential, e.g., OV/SCE

\section{Fig.4. Schematic illustration of surface film on anodically polarized $\mathrm{Mg}$}

